\title{
Fuzzy Modeling of Geospatial Patterns
}

\author{
Alejandra A. López-Caloca and Carmen Reyes \\ Centro de Investigación en Geografía y Geomática \\ "Jorge L. Tamayo" A.C., CentroGeo, \\ México
}

\section{Introduction}

In computer science, the design of intelligent systems able to manage uncertain, indefinite or incomplete information is called Soft Computing (Zadeh 1994). Its aim is to illustrate real problems that are not manageable by conventional techniques. The main techniques that compose Soft Computing are fuzzy logic, neural networks, evolutionary computing and probabilistics. The works published by Prof. Zadeh on fuzzy sets, fuzzy logic, fuzzy systems, neural networks, soft computing and computing with words have had applications in a great diversity of areas-computational modeling, optimizing, planning, control, geospatial analysis, image classification, prediction and image fusion.

Geospatial modeling and retrieving geographical information has become an important part of different areas of knowledge, such as environmental science, urban planning and criminal spatial patterns, among others. This work examines some of the fuzzy tools most commonly used in geospatial modeling for spatial analysis and image processing. We will present a family of models as an alternative to the fuzzy mathematical representation of spatial patterns. This chapter is primarily concerned with spatial pattern methodologies that attempt to describe the arrangement of phenomena in space. In most cases, these phenomena have either point or area features. Point and area analyses use randomness (or a lack of pattern) as a dividing point between two opposite pattern types-dispersed and clustered. This work also presents a general framework (fuzzy data fusion) to combine information from several individual classifications obtained from satellite images in order to recognize spatial patterns and improve spatial pattern extraction.

\section{General framework}

The principal ideas and concepts of fuzzy logic (FL), as shown by Zadeh, are that FL is a precise logic of uncertainty and approximate reasoning (Zadeh 1975, 1976). Zadeh (2010) notes two ideas that FL takes from human capabilities. The first refers to an environment of imperfect information that includes uncertainty, incompleteness of information, conflicting information, partiality of truth and partiality of possibility. The second relates to the capability to perform a wide variety of physical and mental tasks without any measurements or computations. 
For example, when considering fuzzy concepts, we talk about the lack of sharp class boundaries. Thus, the starting point for FL is the fuzzy set concept, where a fuzzy set is a class with unsharp boundaries. FL deals with three basic concepts: graduation, granulation, and precisiation (Zadeh, 2010). The graduation concept is associated with scale- and membership-degree functions. The granulation concept is useful with regard to imprecision, uncertainty and complexity. For precisiation, two approximations are defined-precisiation and imprecisiation, where the former is based on measurements and the latter on perceptions. In fact, the precisiation of meaning has always played an important role in science. Therefore, graduation is related to precisiation and granulation to imprecisiation.

\subsection{Geospatial modeling}

The modeling of natural phenomena requires knowledge of the geographic landscape entities that can be conceptualized in space (places, axiomatic geometry, point-set topology, discrete space, raster/vector), spatial attributes and relations (dimension, connectivity, position, size, location, shape), thematic (natural and conventional objects, classifying objects, pattern recognition) and temporal forms (states, processes and dynamic events). The different fields-geography, biology, hydrology, geology, remote sensing, ecology, and others - select the most important aspects of a phenomenon, i.e., representative variables, to generate data (Jacquez et al., 2000) and perform modeling.

Natural objects that are characterized and define variables may be highly regular, in which a large number of cases are shown as an individual, easy-to-identify elements. Others, however, tend to be highly irregular, fragmented, fuzzier, and have boundaries that are difficult to describe (Galton, 2000). A natural pattern is generated by various processes at different space and time scales depending on the phenomena being investigated; hence the interest in fuzzy modeling for research to illustrate geographic problems (Altman, 1994; Usery 1996; Molenaar \& Cheng, 2000, Croos \& Firat, 2004, Guesgen, 2005).

Problems involving indeterminate boundaries - continuity, heterogeneity, dynamics, scaledependence (Cheng, 2002; Burroughs, 1996) and contiguity - found in the very nature of objects are described below.

Continuity refers to continuous space, which is seamless, i.e., two regions are not separated but rather are distributed in a continuous way in space. In some cases, their distribution does not permit identifying a very precise border because neither the objects nor isolated processes exist. The problem is to represent these objects in a discrete space (Kavoras, 1996). The nature of the object influences how we become aware of the boundaries and their degree of sharpness (Erwig \& Schneider, 1997).

Contiguity measurements evaluate the characteristics of spatial features that are connected, i.e., the evaluation of features that touch one another, that are near one another. Contiguity is desirable to reduce the negative environmental impact on forests, where forest patches affect interior forest habitats.

Spatial heterogeneity is the existence of each object or entity in relation to others, as well as the attributes and qualities of each one of them, and is determined at the moment of mutual interaction. This explains two or various types of vegetation existing in a forest zone and, therefore, describes a heterogeneity problem. The similarity or difference between an entity and its surrounding is a measure of this variation (Reyes-Guerrero, 1986). 
Because dynamic geospatial processes and transformations occurring over long periods of time are not uniform, it is necessary to consider changes in their spatial attributes with their temporal dimensional. For example, geometric spatial changes are investigated with what is known as fuzzy change detection (Molenaar \& Cheng, 2000). Different classes of spatial changes in frontier areas must be considered with respect to diverse observations at different times (changes in dimension, connectivity, size, shape and non-geometrical spatial attributes). These are often difficult to determine because of a lack of dimensions at the time they occur.

Objects are defined according to a geospatial scale and context. The observation is related to the scale at which the object is described (Couclelis, 1996). When having satellite images with different levels of spatial resolution, the identification of more classes will increase by having more detail on these images. The degree of uncertainty of many geographic objects, with respect to the scale of observation, is proposed on the basis of a neural network structure approach (Silván-Cardenas, 2008) and particular data representation models of objects with scale-induced indeterminate boundaries. Using this approach, fuzzy points and fuzzy lines are considered and the connection between the degree of fuzziness and the scale of representation is discussed.

Spatial data are important to diverse studies; in fact, new technology continually enables generating new data. A number of available methods are applied to spatial data, some of which include spatial classification. Nevertheless, difficulties exist that can be conceptualized and modeled with fuzzy concepts, for example, by eliminating strict ideas of encountering boundaries on the geographic objects studied.

In geo-modeling, the utilization of fuzzy concepts with uncertainty problems (Cheng, 2002, Cheng et al 2004) can be divided in four ways:

a. Spatial Incompleteness. Indetermination is related to objects that cannot be separated, or where there is a lack of information (incompleteness) and imprecision. This can be due to the particular information not covering a specific region or the definition of categories that only makes sense in certain parts of the space (e.g meteorological measurements); in remote sensing, for example, the presence of clouds and shadows on satellite images that do not obstruct observation of the zone.

b. Fuzziness. To construct better real-world models, it is necessary to understand the concept of fuzziness as unsharpness of class boundaries, as well as the role of precision in fuzzy borders. In regionalization studies, regions are defined so that every element in the study universe is distinguishable regardless of whether or not it belongs to the region. Geographical problems can undoubtedly benefit from the fuzzy definition. For example, in the study of urban areas, a characteristic of the city is its lack of clear-cut differences in residential areas as well as in land use, for which incorporating the definition of fuzzy regions is therefore more appropriate (Reyes-Guerrero, 1986).

c. Time Incoherence. Temporal uncertainty with respect to time is common when the phenomena observed occurs when precise knowledge is not available about the instant of such information, and it only can be approximated with certain measurements. The value of the information depends on time, since many observed phenomena have temporal space relations, such as vegetation-season. 
d. Other general problems to be considered regarding spatial data are the lack of data or of definition of the object studied, inexact data, inconsistent data from multiple sources, data processing errors, inadequate generalization operations, limitations in the spatial representation scheme and limitations in data acquisition technology (Burroughs, 1996).

\section{Fuzzy spatial clustering}

In general, cluster analysis involves a set of data in groups or clusters that is organized so that items in the same group are similar to each other and different from those in other groups. In spatial information in clustering, different types of clustering analyses have been studied, including spatial clustering (clustering of spatial points), regionalization (clustering with geographic contiguity constraints) and point pattern analysis (hot-spot detection with spatial scan statistics). The use of many of these techniques for hot-spot detection is relatively problematic for several reasons, including the relatively arbitrary definition of the number of clusters to be included and the procedures applied to draw hot-spot boundaries. These contour areas indicate high to low robbery occurrence and, therefore, respond to the demand for public safety or provide alternatives to precisely locate schools in geographic distribution plans.

Fuzzy clustering methods allow objects to belong to several clusters simultaneously with different degrees of membership; in this work, we used Fuzzy C-Means clustering (FCM), (Bezdek, 1973). FCM is a data clustering technique that considers each data point belonging to a cluster to a certain degree, as specified by a membership degree. Two geospatial models with different applications are presented-hot-spot crime detection and educational planning.

\subsection{Spatial analysis of crime}

By definition, a hot-spot is a geographic area that presents a greater concentration of events as compared to its surroundings. It is an important tool for the analysis of point data to describe criminal activities, their geospatial distribution, and especially trends - in order to determine zones more likely to have higher concentrations of criminal events. The algorithms utilized to define a hot-spot may vary significantly when determining optimal and representative clusters-i.e., an adequate grouping must be determined. Generally, analysts must examine a series of possible solutions to spatially determine the optimal configuration; for example, cases using known methods such as hard clustering.

The strict assignment of parameters in the hard-clustering algorithm prevents identifying the optimal number of groups and, therefore, the result is not always realistic. Grubesic (2006) focuses on fuzzy grouping in the case of delinquency.

In order to disclose spatial crime patterns, Lopez-Caloca et al. (2009) tested criminal spatial patterns in the Mexican city of Hermosillo, as well as moving robberies (vehicle theft and public transportation robbery), fixed robberies (household or commercial establishment robberies) and violent robberies. Geo-referenced data from police records are available for each of the events reported during 2005 and 2006. The advantage of fuzzy clusters is a closer estimation of the delimitation of boundaries based on the information, with which to analyze processes in the region. 
The FCM algorithm utilized for this task is based on the minimization of the objective function (eq. 1), which represents the distance from any given data point to a cluster center, weighted by the membership grade of that data point. By iteration, the cluster centers and the membership grade are updated, and the objective function is minimized to find the best location of the clusters.

$$
J_{m}=\sum_{j=1}^{C} \sum_{i=1}^{N} u_{i j}^{m}\left\|x_{i}-c_{j}\right\|^{2},
$$

where

$\mathrm{d}_{\mathrm{ij}}=\left\|\mathrm{x}_{\mathrm{i}}-\mathrm{c}_{\mathrm{j}}\right\|^{2}$, is the distances of the pattern $\mathrm{x}_{\mathrm{i}}$ to the cluster centroid $\mathrm{c}_{\mathrm{j}}$,

\|\| is any norm expressing the similarity between any measured data and the center, $u_{i j}$ is the degree of membership of $x_{i}$ in the cluster $j$,

$x_{i}$ is the $i$-th of d-dimensional measured data, $c_{j}$ is the centroid of the cluster,

$\mathrm{N}$ is the number of data points,

$\mathrm{C}$ is the number of clusters, the parameter $m$ is the weighted exponent for $u_{i j}$ and controls the "fuzziness" of the resulting cluster,

$m$ is any real number greater than 1 and is called the fuzzifier parameter, for which 2 is usually chosen.

Fuzzy partitioning is carried out through an iterative optimization of the objective function shown above, with the updating of membership $u_{i j}$ and the cluster centers $c_{j}$ by:

$$
\begin{gathered}
u_{i j}=\frac{1}{\sum_{u=1}^{C}\left(\left\|x_{i}-c_{j}\right\| /\left\|x_{i}-c_{u}\right\|\right)^{2 / m-1}} \\
\text { where } c_{j}=\frac{\sum_{i=1}^{N} u_{i j}^{m} \cdot x_{i}}{\sum_{i=1}^{N} u_{i j}^{m}}
\end{gathered}
$$

The algorithm is comprised of the following steps:

a. Initialize $U$ (membership matrix), called the fuzzy partition matrix, where $u_{i j}$ denotes the membership degree of a datum $x_{i}$ to cluster $i$,

$$
U=\left[u_{i j}\right] \text { matrix }, U^{(0)} ;
$$

b. Compute the vectors of the center prototypes

$$
C^{(k)}=\left[c_{j}\right] \text { with } U^{(k)} ;
$$

c. Compute the distances: $D_{i j A}^{2}$ 


$$
D_{i j A}^{2}=\left(x_{i}-c_{j}\right)^{T} A\left(x_{i}-c_{j}\right) \text {, a squared inner-product norm. }
$$

Depending on the data and the application, different types of similarity measures may be used to identify classes, where the similarity measure controls how the clusters are formed. Some examples of values that can be used as similarity measures include distance, connectivity, and intensity;

d. Update the partition matrix $U^{(k)}, U^{(k+1)}$;

e. Iteration stop

$$
\text { if }\left\|U^{(k+1)}-U^{(k)}\right\|<\varepsilon \text { then STOP, otherwise return to step } \mathrm{b} \text {. }
$$

This will stop when $\max _{i j}\left\{\left|u_{i j}^{(k+1)}-u_{i j}^{(k)}\right|\right\}<\varepsilon$, where $\varepsilon$ is a criterion between 0 and 1 (fuzzy membership), whereas $k$ are the iteration steps.

Cluster validity refers to the algorithm problem that attempts to find the best fit for the fixed number of clusters and the parameterized cluster shapes. To perform validity measures, different indexes are calculated that indicate the level of partition (Xie et al. 1991). The indexes calculated are: Partition Coefficient (measures the amount of "overlapping" between clusters), Partition Index (the ratio of the sum of compactness and separation of the clusters), Classification entropy (basically a measurement of the fuzziness of the cluster partition only), Separation Index (the inverse of the partition index measurement), Xie and Beni's Index (aims to quantify the ratio of the total variation within clusters and the separation of clusters) and Dunn's Index (identifies compact and well-separated clusters)( Abonyi et al. 2003 \& Balasto B et al. 2003). Table 1 shows the formulas for calculating each index.

The cluster algorithm also attempts to find the best fit for a fixed cluster number and initial conditions; nevertheless, this does not mean that the best fit is significant, since the cluster number could be incorrect. In the case of our data, Figure 1 shows the validation indexes for different fits for the cluster number. The strategy to follow to determine the appropriate cluster number is to calculate a large cluster number and reduce the number based on the data obtained from the validation indexes. It is worth mentioning that each index alone would not be very representative, therfore a set of validations indexes is considered. We take into account that the partitions with fewer groups are better, when the differences between validation values are less. The cluster partition properties are evaluated using PC, CE, SC and the Xie-Beni Index. Cluster properties such as compactness (or variation) and separation are evaluated using the Dunn Index.

Using the data for vehicle crime from 2005-2006 for 437 cases, the PC has a decreasing monotonic trend for $C=4,5$ and $C E$ has a monotonically increasing trend. For $C=22$, the $S$, $\mathrm{SC}$ and $\mathrm{XB}$ indexes arrive at their minimum values of de $0.0001,0.0203$ and 0.0025 , respectively. The Dunn Index was 2.1038, the determination of the optimal number cluster was primarily based on the SC, DI, S and XB indexes, which affirms that the interpretation using different methods makes it possible to assign an optimal number to clusters. 
Partition Coefficient (PC). The optimal number for the cluster corresponds to the maximum PC value. This index tends to decrease, losing a direct connection with the data. $P C(c)=\frac{1}{N} \sum_{i=1}^{C} \sum_{j=1}^{N}\left(u_{i j}\right)^{2}$ where $\mathrm{u}_{\mathrm{ij}}$ is the membership of data point $\mathrm{j}$ in the cluster, $\mathrm{c}$ is the cluster partitions.

Classification Entropy (CE). This index tends to increase until it remains at similar values. $C E(c)=-\frac{1}{N} \sum_{i=1}^{c} \sum_{j=1}^{N} u_{i j} \log \left(u_{i j}\right)$

Partition Index (SC). A lower SC value indicates a better partition.

$S C(c)=\sum_{i=1}^{C} \frac{\sum_{j=1}^{N} u_{i j}^{m}\left\|x_{j}-v_{i}\right\|^{2}}{N_{i} \sum_{k=1}^{C}\left\|x_{k}-v_{i}\right\|^{2}}$ where $v_{i}$ is the cluster center of the $\mathrm{j}$-th cluster

Separation Index (S). The more the clusters are separated, the smaller is $S$, indicating an optimal value for the partition.

$S(c)=\sum_{i=1}^{c} \frac{\sum_{j=1}^{N}\left(u_{i j}\right)^{2}\left\|x_{j}-v_{i}\right\|^{2}}{N \min _{i, k}\left\|x_{k}-v_{i}\right\|^{2}}$

Xie and Beni's Index $(\mathrm{XB})$. The optimal number of clusters should minimize the value of the index.

$X B(c)=\sum_{i=1}^{c} \frac{\sum_{j=1}^{N}\left(u_{i j}\right)^{m}\left\|x_{j}-v_{i}\right\|^{2}}{N \min _{i, j}\left\|x_{k}-v_{i}\right\|^{2}}$

Dunn's Index. To define the optimal number for the cluster, the maximum value for the DI must be obtained.

$D I(c)=\min _{j \in c}\left\{\min _{j \in c, i \neq j}\left\{\frac{\min _{x \in C_{i}} d(x, y)}{\max _{k \in c}\left\{\max _{x, y \in} c^{d}(x, y)\right\}}\right\}\right\}$

where $\mathrm{d}$ is a distance function

Table 1. Different validation measurements proposed in the literature.

Figure 2 (left image) shows a vehicle crime data set for the city of Hermosillo, with the result shown on the city-block network. The right image shows the optimal partition solution, as well as the membership gradient for each cluster. A close-up is represented in Figure 2, where we can see the zones with more crime-streets and areas that need more public safety measures. 

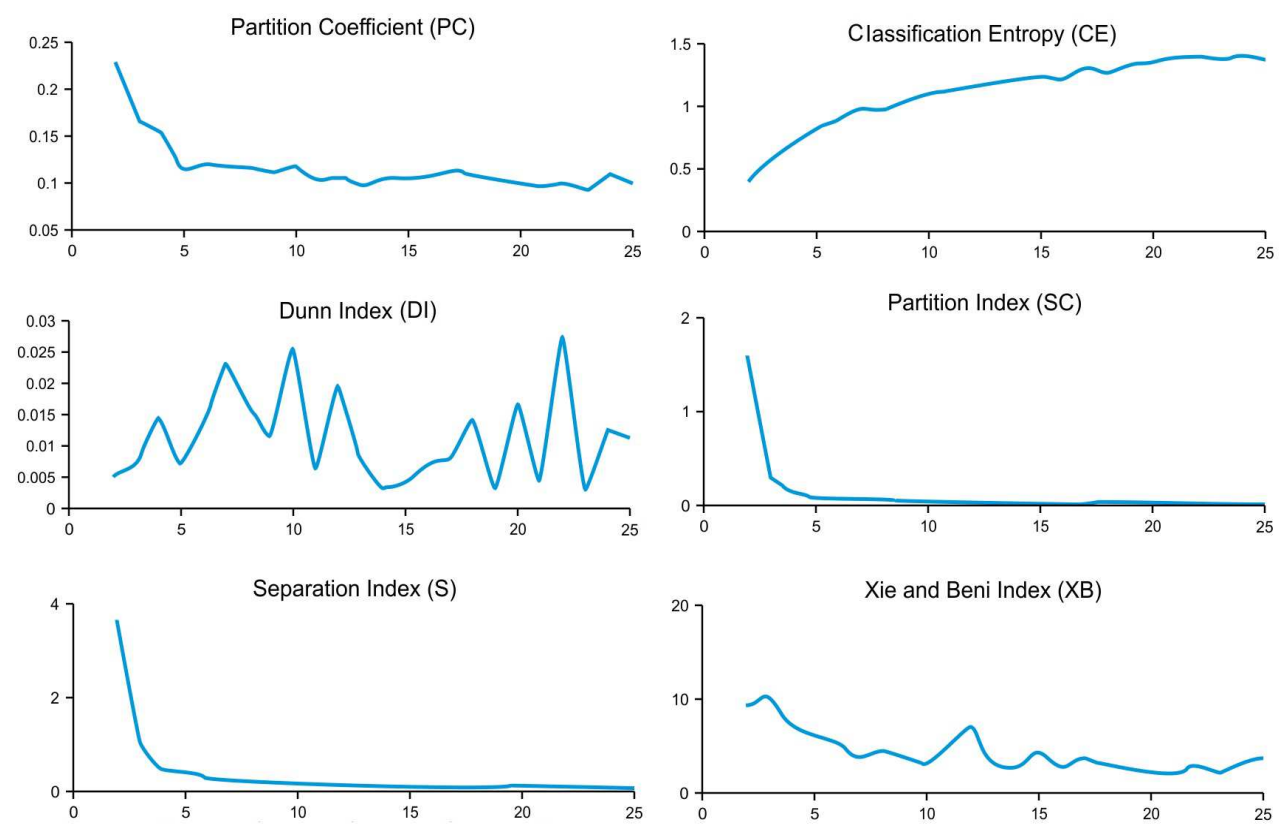

Fig. 1. These graphs show the PC, CE, SC, DI, S and XB indexes. The analysis of all of these makes it possible to determine how many clusters are to be represented.

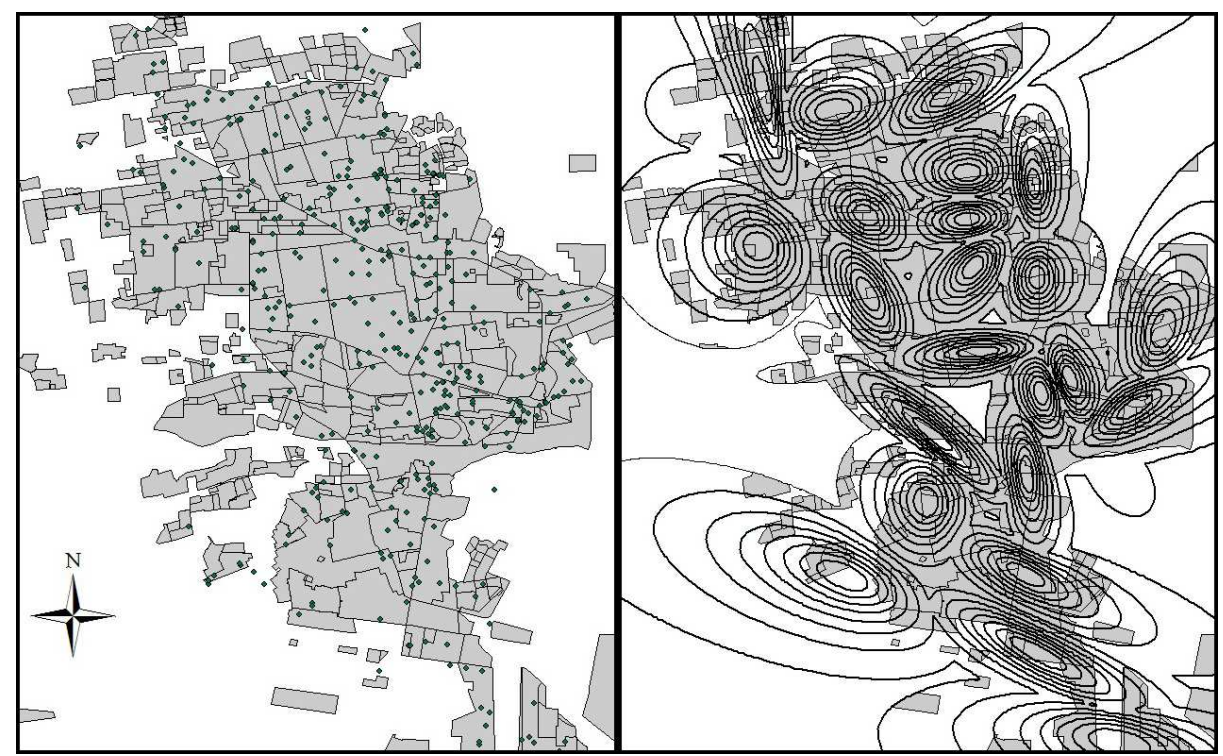

Fig. 2. These figures show the city of Hermosillo Mexico. The left image shows a data set related to vehicle crime; the right image shows the result obtained, of 22 clusters. Data are displayed over the city-block network. 
The crime event is dynamic, thus a more detailed study is needed to consider the temporal portion of the data (months, weeks and days). The membership geovisualization method used was a Sammon mapping (Sammon, 1969), which preserves inter-pattern distances using the Euclidian interpoint distance norm.

$$
S_{\text {sammon }}=\frac{1}{\sum_{i<j} d_{i j}} \sum_{i<j} \frac{\left(d_{i j}-D_{i j}\right)^{2}}{d_{i j}}
$$

where $d_{i j}$ represents the proximity of point data $i$ and $j$ in the original data space and $D_{i j}$ represents the Euclidian distance between mapped points $i$ and $j$ in the projected space. The project is nonlinear and the stress function is defined as:

$$
\sum_{i<j} \frac{\left(d_{i j}-D_{i j}\right)^{2}}{d_{i j}}
$$

Figure 3 shows the geovisualization of the data, where the map's contours are drawn using the selection of membership groups with similar partition values. The areas with greater

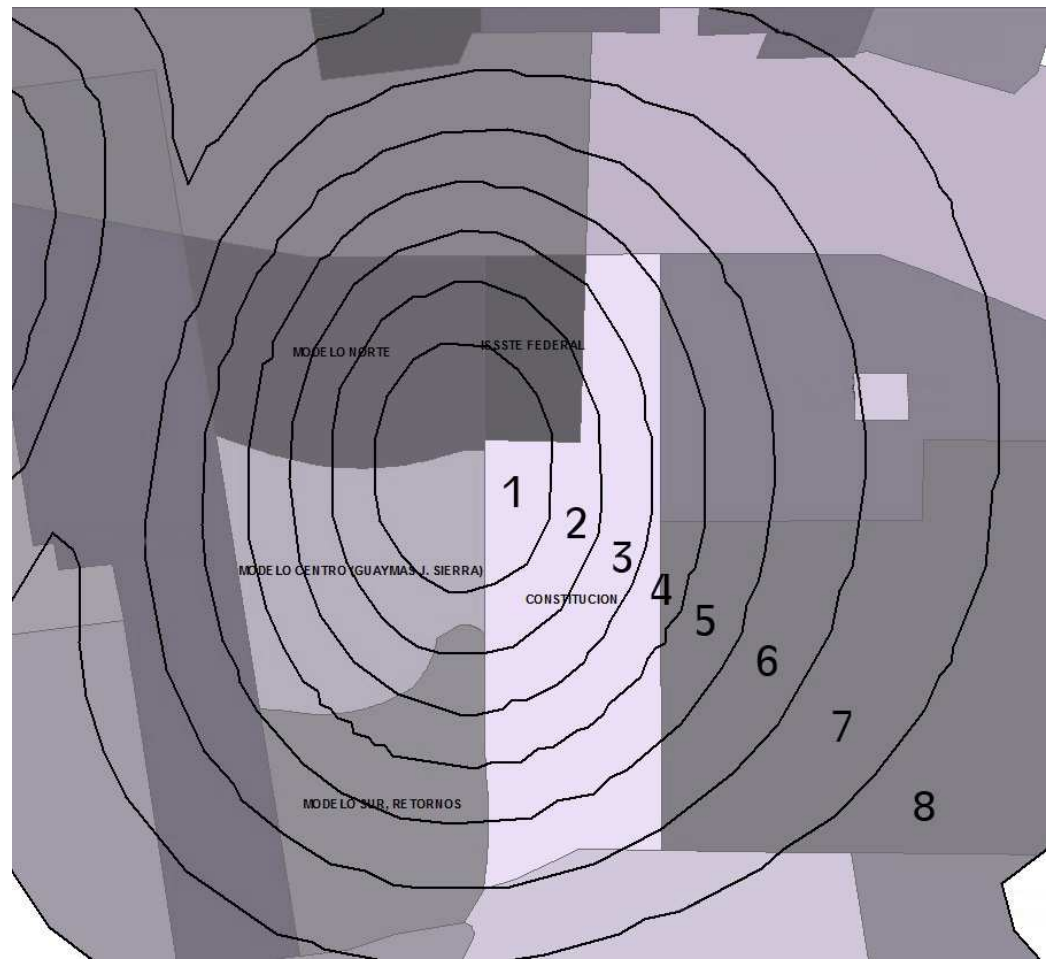

Fig. 3. Geo-projection result of Sammon's mapping. Close-up of hot-spots generated for vehicle crime during 2005-2006. The hot-spot map identifies places and neighborhoods needing measures to resolve public safety concerns, with different degrees of urgency. 
membership are assigned a value of 1 . As the values move away from the ideal value or the center of the set, decreasing values are assigned on a continuous scale from 1 to 0 . The values found in the transition zone are shown as intermediate contours. It can be seen that there are up to four blocks in one cluster (representation of the urban region of the city of Hermosillo). Considering the transition contours and regional representations related to stolen vehicles enables defining better strategies to address the problem. The figure numerically shows the monitoring zones according to different degrees of urgency.

In practice, data for different criminal acts can occur at any time; the data are dynamic and changing. Working with fuzzy hot-spot information makes it possible to consider a spatial distribution with grades of membership, enabling administrators and professionals in crime prevention to use the data as a detection strategy as well as to spatially identify different priority zones, taking into greater account urban geographic spaces.

\subsection{School infrastructure analysis}

One factor in the level of development of a society is the degree of education. The topic of education has two spatial aspects: first, the identification of zones covered by elementary schools (primary and secondary school categories) and second, the identification of the deficit, based on the comparison of the number of allotments offered versus the population density throughout the zone.

Figure 4 shows the areas in terms of the presence of private and public elementary schools in the Alvaro Obregon district of Mexico City. In fuzzy clustering, the data points for the primary location may belong to more than one cluster, and associated with each of the points are membership grades indicating the degree to which the data points belong to the different clusters.

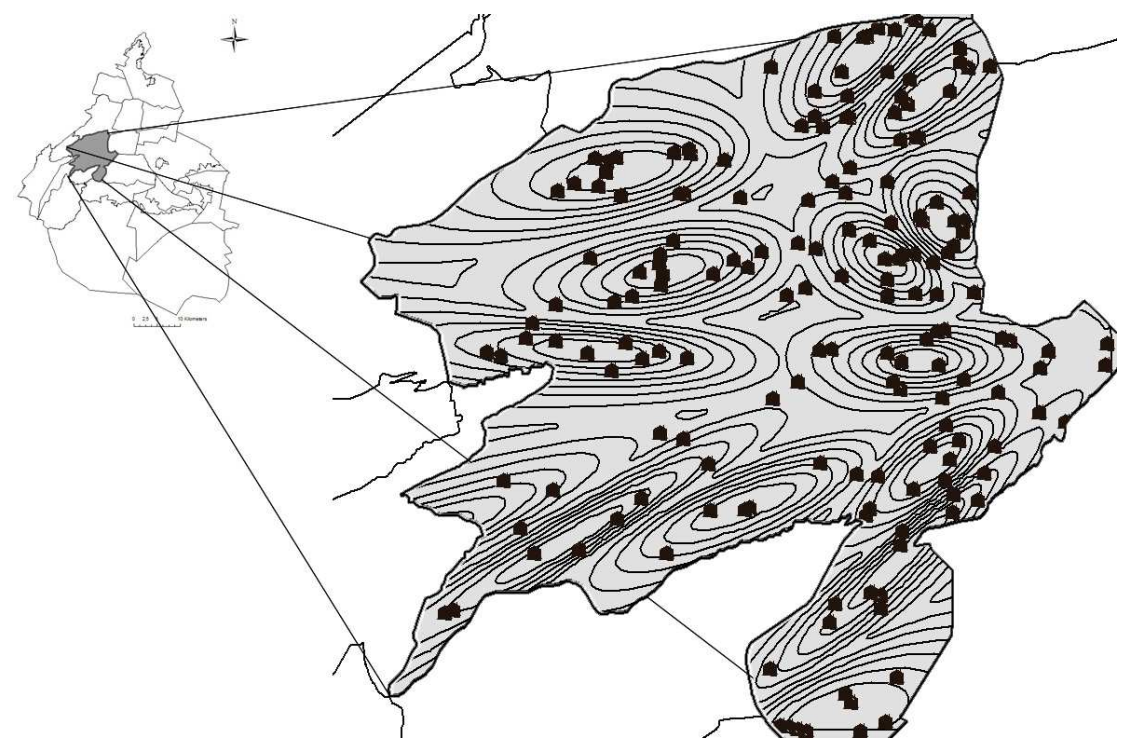

Fig. 4. The Alvaro Obregon district in Mexico City. Zones with elementary school coverage. 
The membership zones obtained with fuzzy clusters indicate that 13 areas are benefited by schools. The validation of the optimal clusters is shown in Figure 5. PC has a decreasing monotonic trend and $\mathrm{CE}$ has an increasing monotonic trend, representing the increase in the cluster number. In both cases, the connection with the data structure is not direct. SC, S and $\mathrm{XB}$ have values of $0.0003,0.0341$ and 1.8785 , respectively, and arrive at a local minimum. The DI has a maximum value of 0.524 and affirms the number $C=13$. With the different methods of analysis, 13 is chosen as the optimal cluster number.
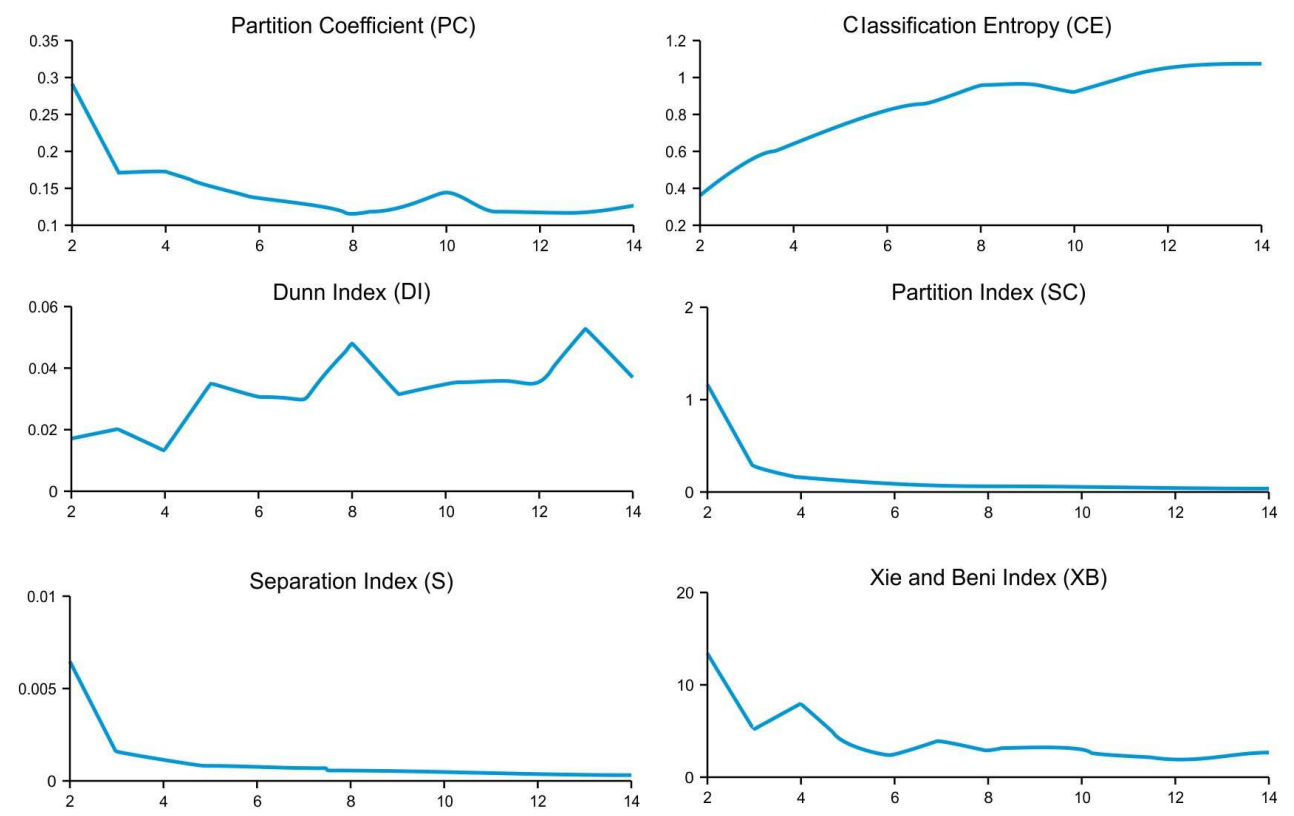

Fig. 5. Graphic representation of the validation index values used to find the optimal cluster number.

To identify service offerings and demand, and whether they are sufficient, the spatial distribution of the population density was analyzed. The 3 highest membership levels next to 1 were determined for the number of children between 6 and 12 years of age located in this zone. The results show the fact that the educational establishments are not spatially distributed according to the population density of these children, and that the potential population of children between 1 and 4 years of age calls for increasing these services in the future. Zones with low membership are sectors where measures could be taken to avoid this school deficit (Table 2). The results shown in Table 2 indicate that this type of analysis enables defining the geospatial problematic at the neighborhood as well as the street level.

The FL tool is fundamental to strategies for locating elementary schools to improve services. A study of this type must take into account the number allotments offered by the educational institution.

The area of influence of an educational establishment does not necessarily have a circumferential shape. But the existence of topographic and geographic borders must also be 
considered because they sometimes constitute significant limitations in identifying a student's route to his or her school. A diagnostic for the student's travel distance network is shown by Reyes-Guerrero (1986), who defines the degree of membership in a class for each one of the nodes on the graph (nodes represent the elements that belongs to each region), making it possible to define neighborhood relationships.

Figure 6 represents the analysis of distance from cluster centers, considering which of the clusters with greater school density are in closer proximity to each other. This analysis makes it possible to prevent excessive proximity in order to avoid, as much as possible, a spatially inadequate school distribution. In fact, the demand for elementary schools was so

\begin{tabular}{|c|c|}
\hline $\begin{array}{c}\text { Areas with } \\
\text { current } \\
\text { educational } \\
\text { services }\end{array}$ & $\begin{array}{c}\text { Dolino de Rosas-Mixcoac; Molino de Santo Domingo-Acueducto; Olivar de } \\
\text { los Padres; Piloto Adolfo López Mateos; Pueblo Santa Fe-Gamitos; San } \\
\text { Angel -Pogreso; San Bartolo Ameyalco; Torres de Potrero; Alfonso XIII; } \\
\text { Bosques 1A-2A seccion; Ceguayo-Cuevitas; Jardines del Pedregal- CU; } \\
\text { Jardines del Pedregal-Loreto }\end{array}$ \\
\hline $\begin{array}{c}\text { Areas with } \\
\text { deficit of } \\
\text { educational } \\
\text { services }\end{array}$ & $\begin{array}{c}\text { Presidentes - Golondrinas - Lomas de Capula; Colinas de Tarango - } \\
\text { Lomas de Tarango; San Clemente norte y sur; Cedros }\end{array}$ \\
\hline
\end{tabular}

Table 2. Distribution of educational services for children between 6 and 12 years of age.

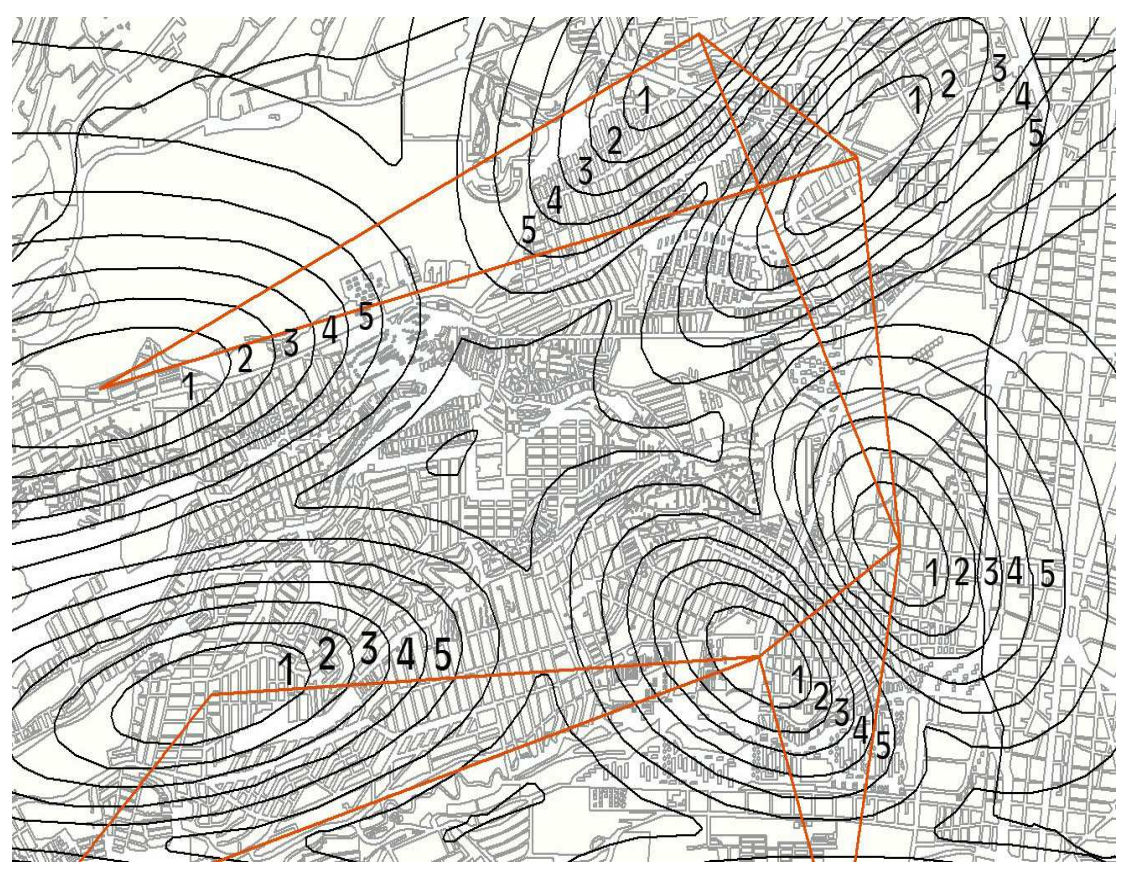

Fig. 6. Example of the distance analysis based on cluster centers; zones with less membership represent those with low elementary school coverage for the population. 
great that establishing one was considered beneficial to the local community. Identifying the precise location of the school is now important. Educational planning requires a geographic distribution study of the current density of schools.

\section{Fuzzy-based data fusion model}

Though the concept of data fusion is easy to understand, it varies from study to another. Data fusion has also been referred to as merging, combination, synergy and integration. In terms of formal data fusion tasks, it is desirable to design an architecture that combines information from different sources, thus obtaining high-quality information. Current fusion methods utilize tools such as weighted average, neural networks (multi-sensory fusion), rules-based knowledge, wavelets (multiresolution fusion), graph pyramids, and more recently, fuzzy logic. Data fusion is frequently described in literature as occurring on three levels: pixel, attribute and decision (Pohl et al. 1998, Wald 2002, López-Caloca 2006). A general idea about how different authors handle these fusion levels is described below.

a. Pixel level. Images come from different sources, which are combined from pixel to pixel. The fusion process should preserve the relevant information from the entered images on the synthetic image (pattern preservation). Although the word "pixel" is not really adequate, the pixel is the basis for the information and does not have semantic meaning.

b. Attribute level. The figures (geometric, structural or spectral) are drawn from crude images and fused afterwards. Fusion at the figure level requires recognizable objects extracted from diverse data sources using a segmentation process. The figures correspond to characteristics extracted from the initial images, such that they provide form; selection is based on the practical use of the application. The classified maps are combined and the spacial information related to each pixel's neighbor is taken into account in order to improve the fit.

c. Decision level. Decision fusion can be defined as the process of fusing information from several individual data sources after each data source has undergone a preliminary classification. The results of classification are combined by using their weighted significance.

For hard classifiers, image pixels are assigned to a given category, although errors in pixel classifications exist (pixels that may belong to a different category). When assigning a pixel to a class, there is a risk of it being assigned to a class to which it does not belong (misclassified) or pixels may be over-classified. Fuzzy classification considers that one category admits a property between 0 and 1 . The idea is to permit simultaneous assignment to various categories with different degrees of property, and later reclassify the fuzzy boundaries.

The fuzzy classification problem has been extensively studied in remote sensing (Lizarazo \& Elsner, 2011, Amici et al. ,2004). A fuzzy classifier is mainly applied when the data have a high degree of spectral mixture. Shackelford and Davis (2003) present a fuzzy logic classifier and object-based approach. The individual pixels in the image are first classified with a fuzzy classifier, making use of both spectral and spatial information. The segmented image is then used with additional object feature information to classify the image objects. Huntsherger (1985) described the application of the technique, called iterative fuzzy clustering, with the aim that the segmentation process not be affected by noise and 
degradation from image acquisition. Likewise, combinations such as fuzzy-support vector machine (F2-SVM) (Borasca, 2006) enable demodulating the relations between one pattern and the proposed classes in the F2-SVM framework. Other classification approaches attempt to take advantage of the strengths of each algorithm. For example, in the combination of two techniques-fuzzy topology and the Maximum Likelihood Classifier (MLC) (Liu et al., 2011), known as FTMLC - one membership function is created for each pixel using FTMLC and the pixels with greater membership are assigned a certain class, while those with less membership are left at the boundaries for a later process. Connectivity is sought for pixels at the boundaries with respect to their 8 neighbors, in such a manner that the one with the higher number of connected pixels belongs to that class. As a result, pixels on fuzzy borders are re-classified and, therefore, are given a higher assignment.

In the search for better solutions to problems of imprecise information, data fusion emerges as an alternate tool which, for example, can use the strengths of different classifiers in order to obtain a better approximation, with the resulting classification proportions resulting in less redundancy and complementary information.

The aggregation of information from multiple sources using a fuzzy system requires specifying the value of the input variable, membership functions and production rules (Klein, 2004, Raol, 2011). Each data source furnishes one or various admissions. An expert develops the standards specifying the outlet actions in terms of fuzzy sets, combinations of fuzzy input, and the definition of property functions that define the property of the fuzzy sets for output.

Fusion tasks at the pixel level have applied FL and neural fuzzy algorithms (Zhao et al., 2005, Meitzler, 2002, Singh, 2004). Their implementation considers two or more admission images for the fuzzy method. The implementation is carried out by assigning the admission variables with the same image size, deciding the number and type of functions for membership to the admission images, applying the fuzzy action using the rules developed in the pixel values of each admission image - which provides a fuzzy set represented by a membership function - and, lastly, applying the defuzzification of the outlet image.

In the fusion framework at the decision level, fuzzy algorithms have also been successfully used in various applications. Chanussot et al. (1999) propose a variety of strategies to combine images based on fuzzy fusion techniques with the aim of drawing roads. As in the case of fuzzy modeling, they combine the results from various detectors of boundaries. The neural-fuzzy-fusion method (NFF) combines a set of fuzzy classifiers in a system called a multiple classifier system (MCS). The application of this method to remote sensing images has demonstrated that the NFF-MCS produces good results (Shankar et al., 2006).

Support vector machines (SVM) have been applied to different classification problems (Mounrakis et al., 2010). The precision of these generally surpasses conventional algorithms. Fauvel et al. $(2006,2007)$ conducted fusion processes by combining spectral and spatial information. While the SVM enables working with the spectral information of an image, the spatial information is defined by means of morphological profiles, with the fusion process performed using different voting schemes (for example, absolute maximum and majority voting). Mathieu Fauvel et al. (2007) discuss the optimization of classifications of urban zones with high-resolution images, considering the use of various classifiers (conjugate gradient neural network and a fuzzy classifier). The inputs for the fusion process were the 
posterior probabilities from the outputs of the neural network and the membership degrees for the fuzzy classifier; i.e., the methodology consists of processing the data with each classifier alone and assigning to the algorithms each pixel's grade of membership for the classes considered. Then, the combination rule from the fuzzy decision is utilized to combine the results furnished by the algorithms, in accordance with the capabilities of the classifiers used. When modeling the output classifier, such as a fuzzy set, certainty is measured by the grade of uncertainty and the estimates of the global exactness of each classifier. The results can integrate a good deal of complementary information for the final classification process.

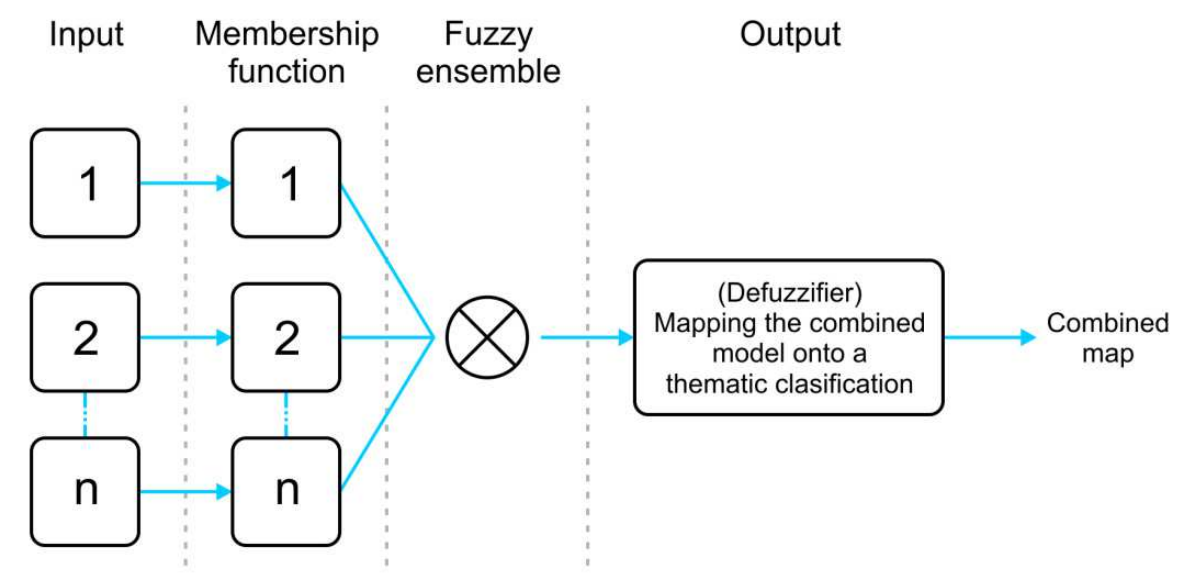

Fig. 7. Experimental fuzzy fusion scheme

Figure 7 shows a proposed fuzzy fusion technique. Images were classified with the Support Vector Machine (SVM) algorithm. In SVM, a function set is analyzed with this classifier, in such a manner that the function is approximated with less discrepancy between the a priori knowledge and the training data. Classes are divided in feature space; SVM separates two class sets by means of a hyper-plane $(\mathrm{H})$ of linear or nonlinear functions. Available kernels include linear, polynomial, radial basis function and sigmoid. The kernel transformation allows for finding a new feature space in which linear hyper-planes are appropriate for class separation. In order to avoid or minimize the former errors, at the moment of adjusting the data it searches for the Structural Risk Minimization (SRM). In this work, two kernels were utilized-sigmoid and polynomial. The literature reports that both segmentation results present high precision. For the purposes of this task, the fusion of both segmentation results and the application of our proposed fuzzy fusion techniques are proposed. The resulting SVM classifications furnish redundant and complementary results. The methodology consists of data processing with each classifier and assigning each pixel's membership grade to the algorithms for the classes being considered; these are the inputs in the fusion process. The classified images were re-mapped into membership values ranging from 0 to 1 , using a specified fuzzy function; in this case, a linear transformation.

The fuzzy fusion technique is used to combine two or more fuzzy membership results using fuzzy as a simple operator to create, in the case of suitability, the most suitable model. The 
fuzzy sets A and B will return the minimum value of the sets of cells located at the standard intersection $(A \cap B)(x)=\min [A(x), B(x)]$. Finally, the defuzzification action is conducted by assigning the segmented regions to each class. Defuzzification is a process that converts a fuzzy set or fuzzy number into a crisp value or number.

The proposed method represented in Figure 7 is applied using images in Figure 8. For the purpose of evaluating the combination of elements extracted during the segmentation process, segmentation with SVM (sigmoid) was applied to images $8 \mathrm{~B}$ and $8 \mathrm{C}$. These images consist of information with little definition, but include complementary information. Fuzzy fusion was applied later, and the result was evaluated with the segmentation of reference image 8A.
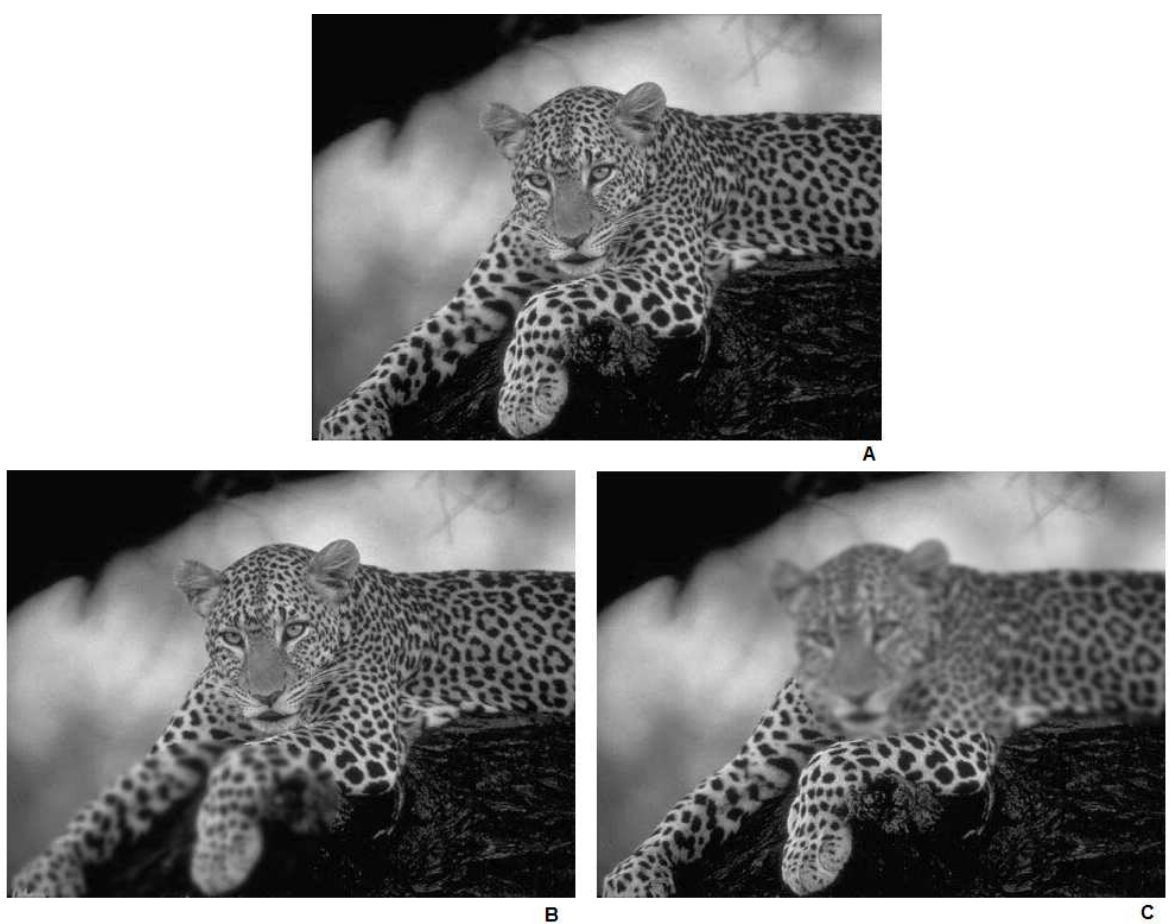

Fig. 8. Original images. A) reference, B) Image degraded in the leopard's extremities and C) image degraded in the face of the leopard. (Image example, Barnea \& Hassner, 2006).

All images were segmented into 6 classes (Figure 9) that define the background of the image and the leopard shape (spots, face, skin), where image $C$ is a classified reference image, A and B are classified results of the images with lack of sharpness and information, image $\mathrm{D}$ is a result of applying the fusion images from $\mathrm{A}$ and $\mathrm{B}$ using the fuzzy methodology. The segmentation accuracy (SA) was calculated, which is defined as the percentage of the number of correctly classified pixels to the total number of pixels. The well-classified pixels were considered using reference image C. The SA for image A was $89.60 \%$; the SA for image B, $83.12 \%$, and finally, the SA for the fusion image D was $87.14 \%$. 
This approach enables combining objects extracted after the segmentation process, improving the class boundaries and thereby having better knowledge of the objects observed when all the information is not originally available. The method was also applied with SPOT-5 satellite images.

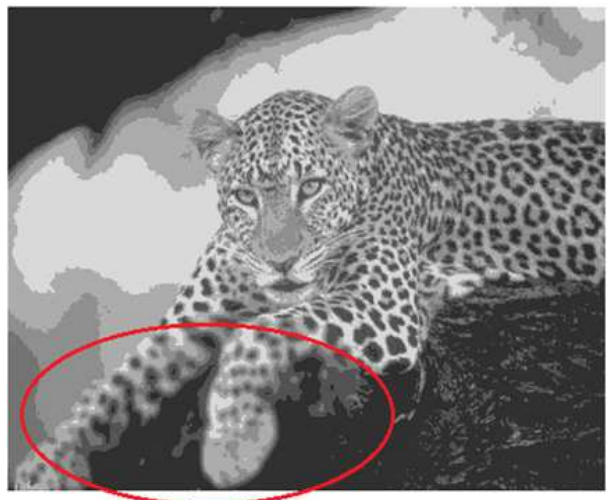

A

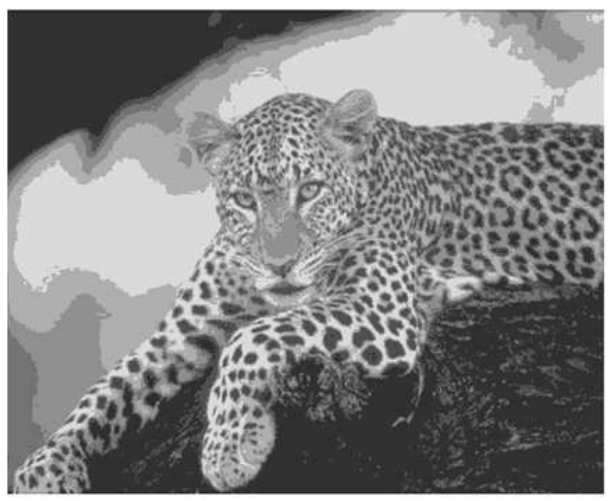

C

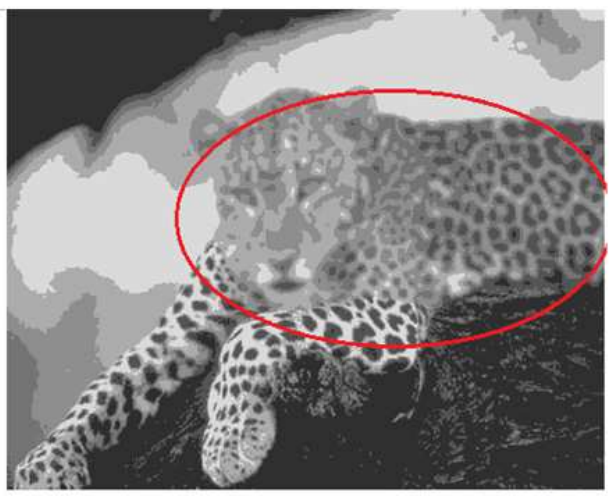

B

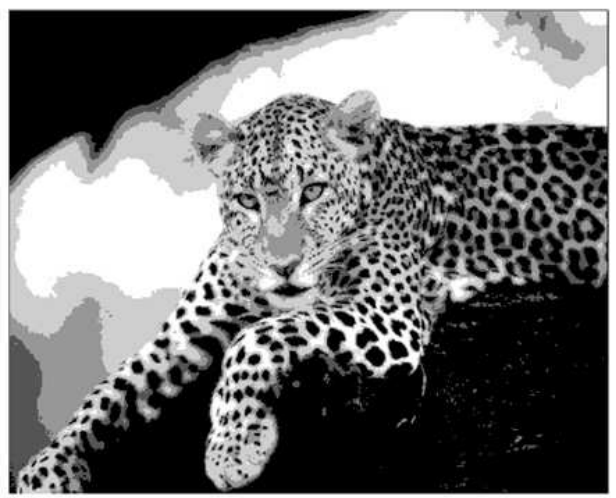

D

Fig. 9. A) and B): Images with less information are shown inside circular areas with less information, C) reference image and D) image fusion result.

We mentioned previously the interest in the fusion of images using fuzzy tools and applying them to remote sensing images. Fuzzy fusion techniques enable alleviating the problem of improving real and complex classifications as well as improving and complementing information. This approach shows the fusion of two SVM classifications by applying the sigmoid and polynomial kernels to a SPOT image with a landscape representative of an agricultural area. These results are shown in Figure 9B and 9C, with the fusion shown in 9D. 
In order to conduct quantitative comparisons of the two algorithms, the concept of uniformity (Levine \& Nazif, 1985, Cheng-Chia et al. 1997) was applied. This method is applied when a reference image or real data do not exist. Let I be the segmented image and $S_{I}$ the area of the entire image. $R_{i}$ denotes the set of pixels in region i. The uniformity of a segmentation result is defined by:

$$
\mathrm{U}=1-\frac{\sum_{i=1}^{S} \sigma_{i}}{K}
$$

where $\mathrm{S}$ is the number of classes, $\sigma^{2}$ denotes $i$ within-class variance of the $\mathrm{i}$-th class, $\mathrm{K}$ is a normalization factor that limits the maximum value of the measurement to 1 . We find that the proposed fuzzy fusion method obtains a similar uniformity value $(0.889)$ with respect to

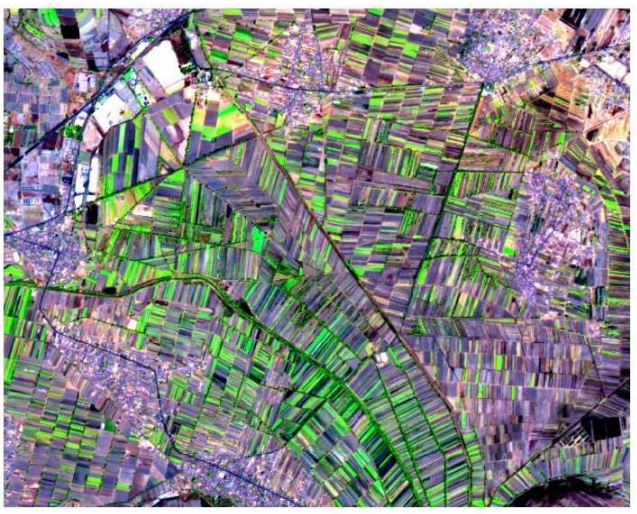

A

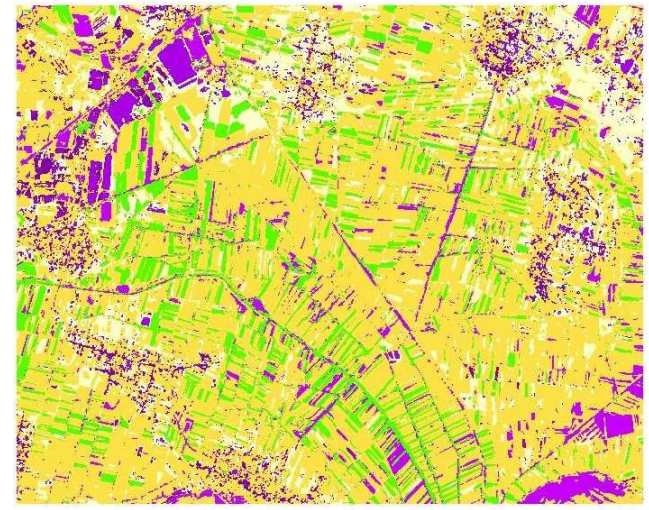

C

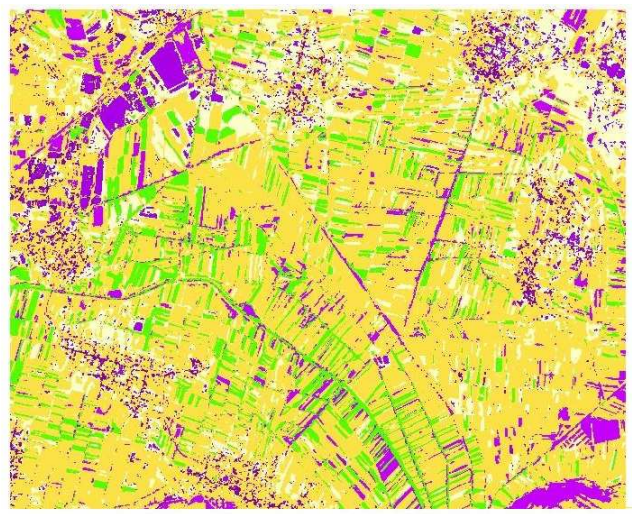

B

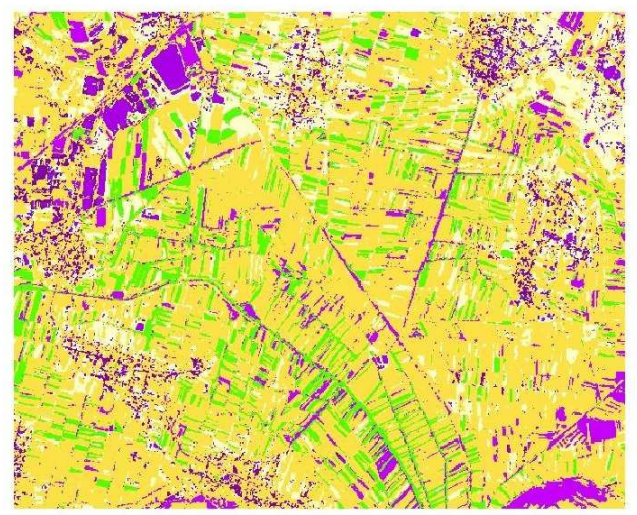

D

WET
AGRICULTURE
FIELDS $\quad \square$ BARE SOIL $\quad \square \begin{aligned} & \text { AGRICULTURE } \\ & \text { FIELDS }\end{aligned}$

Fig. 10. A) Original, B) SVM (sigmoid kernel ), C) SVM (polynomial kernel) and D) fuzzy fusion result 
the other SVM classifiers (sigmoid and polynomial kernel), which obtain uniformity values of (0.840). One last measurement that can be performed with the error of the results is the verification process, by calculating overall reliability. Photo interpretation was used, such as real land - as well as the verification of maps classified based on the definition of proposed thematic categories (agriculture fields, bare land, among others). The overall reliability was $84.8 \%$ for SVM (sigmoid), $83.9 \%$ for SVM (polynomial), and lastly, $84.4 \%$ for the fuzzy technique. The results indicate that fuzzy fusion has an acceptable thematic quality and may be an alternative to integrate information, in this example, and to obtain well-defined images.

This section illustrates a simple fusion model with the application of fuzzy concepts, shows its function in providing complementary information (Figure 9) and presents another example applied to geospatial data (Figure 10), such as thematic classification maps obtained from a single satellite image, which can be combined to reduce uncertainty. With this example, we demonstrate that fusion along with fuzzy techniques make it possible to model spatial properties.

\section{Conclusion}

This work demonstrated the advantages of utilizing fuzzy methods for spatial analysis and image processing applications. For crime analysis, we were able to identify patterns by looking at the geography of the incidents and identifying hot-spots. Zones with a high spatial concentration of schools were also identified, as well as the existence of geographic areas needing this service. Finally, the application of fuzzy fusion enabled combining information within the framework of fuzzy modeling in order to improve and complete information, as is the case when using different classifiers.

It is therefore possible to conclude from these examples that the models designed and applied in this work allowed us to identify different aspects of spatial patterns, where the main elements of the study were part of the geographical landscape.

For geospatial analysis, the challenge to explore more applications with fuzzy methodologies continues to evolve. In the next phase, other elements of geospatial structures could naturally be explored, such as the causes of certain phenomena in the regions where crime occurs, in educational planning or in the functioning of social urban processes. The generation of robust scientific knowledge is needed in order to address problems that in the past have not been possible to study with non-fuzzy computational algorithms.

Although several mathematical models have been designed for geospatial applications, topological concepts and geographic neighborhood models using fuzzy set tools have received little attention in the area of modeling. Future work will integrate the idea of fuzzy topology proposed by Reyes-Guerrero (1986) to include the topological space as a new mathematical structure, applying the design of fusion and classification algorithms to topology, contiguity and the degree of membership to a border or interior region.

\section{Acknowledgment}

The authors thank to Dr. Elvia Martínez, José Manuel Madrigal, Camilo Caudillo and José Luis López, Rafael García for their contributions to this work. 


\section{References}

Abonyi J \& Szeifert F.,(2003), Supervised fuzzy clustering for the identification of fuzzy classifiers, Pattern Recognition Letters, Vol. 24, No.14, pp. 2195-2207.

Altman D.( 1994), Fuzzy set theoretic approches for handling imprecision in spatial analysis, Int. J. Geographical Information systems, Vol.8, No.3, pp.271-289.

Amici G., Dell' Acqua F., Gamba P., and Pulina G., (2004), A comparison of fuzzy and neurofuzzy data fusion for flooded area mapping using SAR images, International Journal of Remote Sensing, vol. 25, no. 20, pp. 4425-4430.

Barnea A. and Hassner T. ( 2004-2006) Image example Available from: http://www.wisdom.weizmann.ac.il/ vision/alumni/hassner/Fusion/\# examples

Balasto B., Abonyi J., and Feil B., (2003), Fuzzy Clustering and Data Analysis toolbox, for use with matlab, Veszprem University, Hungary , Available from: http://www.mathworks.com/matlabcentral/fileexchange/7473.

Bezdek J.C., (1973), Fuzzy mathematics in pattern classification, Ph.D. dissertation, Cornell Univ., Itheca, NY.

Borasca, B.; Bruzzone, L.; Carlin, L.; Zusi, M. (2006), A fuzzy-input fuzzy-output SVM technique for classification of hyperspectral remote sensing images, In Signal Processing Symposium, NORSIG 2006. Proceedings of the 7th Nordic, pp. 25,ISBN:1-4244-0412-6.

Burrough P.A. (1996), Natural Object with indeterminate Boundaries, In Geographic objects with indeterminate boundaries. GISDATA2, Edited Burrough P.A. \& Frank A.U., Series Editors Masser I. and Salgé F. Taylor \& Francis. Printed in Great Britain. ISBN 0-7484-0386-8, p. 3,71.

Chanussot J, Mauris G, Lambert P., (1999), Fuzzy fusion techniques for linear features detection in multitemporal SAR images, IEEE Trans Geosci Remote Sens. Vol.37, No.3, pp. 2287-2297.

Cheng T., (2002), Fuzzy Objects: Their Changes and Uncertainties, Photogrammetric Engineering \& Remote Sensing,. Vol. 68, No. 1, pp. 41-49.

Cheng T., Fisher P \& Zhilin L.,(2004) Double vagueness: uncertainty in multi-scale fuzzy assignment of duneness , Geo-Spatial Information Science ,volume 7, Number 1, 5866, DOI: $10.1007 /$ BF02826677.

Cheng-Chia Chang, Ling-Ling Wang, (1997), A fast multilevel thresholding method based on lowpass and highpass filtering, Pattern Recognition Letters, Vol. 18, pp. 14691478

Couclelis H., (1996), Toward an operational typology of geographic entities with ill-defined boundaries. In:. Geographic objects with indeterminate boundaries, Burrough P.A. \& Frank A.U. , (Eds), pp. 71-85, (London: Taylor \& Francis). Cross V., Firat A., (2000), Fuzzy objects for geographical information systems, Fuzzy Sets and Systems, Vol. 113,pp 19-36.

Erwig M., \& Schneider M, (1997), Vague Regions, In: 5th Int. Symp. on Advances in Spatial Databases (SSD'97), LNCS 1262, 298-320

Fauvel, M. Chanussot, J. Benediktsson, J.A. , (2006), Decision Fusion for the Classification of Urban Remote Sensing Images, IEEE Transactions on Geoscience and Remote Sensing, Vol. 44 , No.10, pp. 2828 - 2838, 
Fauvel, M. Chanussot, J. Benediktsson, J.A.,(2007), Decision fusion for hyperspectral classification, In Hyperspectral data exploitation, theory and application, edited by Chang C.I., , pp.315-351. John wiley \& Sons,Inc, ISBN:978-0-471-74697-3

Galton A., (2000), In Qualitative Spatial Change pp.121,129. Oxford University press. ISBN 0-19-823397-3. New York.

Grubesic T.H.,(2006),On the Aplication of Fuzzy Clustering for Crime Hot Spot Detection, Journal of Quantitave Criminology, Vol. 22, No 1.,pp. 77-105.

Guesgen H.W., Fuzzy Reasoning about Geographic Regions, (2005),In Fuzzy Modeling with Spatial Informationfor Geographic Problems , Editors: Petry F.E., Robinson V.B., Cobb M.A., pp.1-14, Springer Berlin Heidelberg, ISBN 3-540-23713-5 , New York.

Huntsherger T.L., Jacobs C.L., Cannon R.L.,(1985), Iterative fuzzy image segmentation Pattern Recognition, Vol. 18, No. 2, pp. 131-138.

Jacquez G.M., Maruca S.,Fortin M.J.,( 2000), From fields to objects: A review of geographic boundary analysis. J. Geograph Syst, Vol.2, pp.221-241.

Kavoras M.,(1996), Geoscience modeling: from Continuous fields to entities, In Geographic objects with indeterminate boundaries. GISDATA2, Series Editors Ian Masser and Francois Salgé. Taylor \& Francis. V, ISBN 0-7484-0386-8, Great Britain.

Klein L.A.(2004), In Sensor and Data Fusion. A tool for information assessment and decision Making. SPIE Press, Bellingham, pp. 258-259, 296. ISBN 0-8194-5435-4, Washington USA.

Levine, M.D., Nazif, A.M., 1985. Dynamic measurement of computer generated image segmentation, IEEE Trans. Pattern Anal. Machine Intell. Vol. 7, No.2,pp.155-164.

Liu K., Shi W., Zhang H.,(2011), A fuzzy topology-based maximum likelihood classification, ISPRS Journal of Photogrammetry and Remote Sensing, Vol.66, pp. 103-114.

Lizarazo I. \& Elsner P., (2011), Segmentation of Remotely Sensed Imagery: Moving from Sharp Objects to Fuzzy Regions, In Image Segmentation, Edited by: Pei-Gee Ho, Publisher: InTech, ISBN 978-953-307-228-9.

López-Caloca A. A., Martínez-Vivero \& Chapela-Castañares J.I. (2009), "Application of a clustering-remote sensing method in analyzing security patterns", Proc. SPIE 7344, 734407; doi:10.1117/12.818911.

López-Caloca A.A. (2006), Advanced Image Fusion Techniques for Remote sensing. Thesis doctor of engineering, UNAM, Mexico.

Meitzler T., Bednarz D., Sohn E.J., Lane K., Bryk D., Kaur G., Singh H., Ebenstein S., Smith G.H., Rodin Y., Rankin J.S., (2002), "Fuzzy Logic based Image Fusion." Aerosense, Orlando April 2-5.

Molenaar M. \& Cheng T., (2000), Fuzzy spatial objects and their dynamics, ISPRS Journal of Photogrammetry \& Remote Sensing, Vol. 55, pp. 164-175.

Mountrakis G., Im J., Ogole C. (2011), Support vector machines in remote sensing: A review, ISPRS Journal of Photorammetry and Remote Sensing , Vol.66,pp. 247-259

Raol J. R. , (2011), In Multi-Sensor Data Fusion with MATLAB, CRC Press Taylor \& Francis Group, pp. 215-351.

Reyes-Guerrero M. del C., (1986), Neighborhood models: an alternative for the modeling of spatial structures, Thesis doctor of philosophy, Simon Fraser University. pp. $65,109,123,156$, Canada. 
Pohl, C. and van Genderen, J.L. (1998), Multisensor image fusion in remote sensing : concepts, methods and applications, International journal of remote sensing, Vol.19, No. 5, pp. 823-854.

Sammon J.W Jr., (1969), A nonlinear mapping for data structure analysis, IEEE Transactions on Computers, Vol. C-18, No.5, pp.401-409.

Shackelford A.K., \& Davis C.H., (2003), A Hierarchical Fuzzy Classification Approach for High-Resolution Multispectral Data Over Urban Areas, IEEE Transactions on Geoscience and remote sensing, Vol. 41, No.9, pp.1920- 1932.

Shankar B. U, S.K., A. and Bruzzone L.,(2006), Remote Sensing Image Classification: A Neurofuzzy MCS Approach, Computer Vision, Graphics and Image Processing In Lecture Notes in Computer Science, Vol.4338, pp. 128-139, DOI: 10.1007/11949619_12 .

Silván-Cárdenas J.L., Wang L., Zhan F.B.,(2008), Representing geographical objects with scale-induced indeterminate boundaries: A neural network-based data model, International Journal of Geographical Information Science,vol.1,p p. 1-24, ISSN 13658816.

Singh, H.; Raj, J.; Kaur, G.; Meitzler, T.; (2004), Image Fusion using Fuzzy Logic and applications, Fuzzy Systems, On Proceedings. 2004 IEEE International Conference, Vol. 1, pp. 337 - 340, ISSN: 1098-7584.

Usery E.L., (1996), A conceptual framework and fuzzy set implementation for geographic features. In: P.A. Burrough and A.U. Frank (Eds). In Geographic objects with indeterminate boundaries (London: Taylor \& Francis), pp. 71-85.

Wald L., 2002. Data Fusion. Definitions and Architectures - Fusion of Images of Different Spatial Resolutions. Presses de l'Ecole, Ecole des Mines de Paris, Paris, France, ISBN 2-911762-38-X, $200 \mathrm{p}$.

Xie X.L., and G. A. Beni G.A., (1991), Validity measure for fuzzy clustering, IEEE Trans. PAMI, Vol. 3, No. 8, pp. 841-846.

Zadeh, L.A., (1975), Fuzzy logic and approximate reasoning, Synthese, Vol. 30, pp. 407-428.

Zadeh, L.A., (1976), A fuzzy-algorithmic approach to the definition of complex or imprecise concepts, International Journal of Man-Machine Studies , Vol.8, pp. 249-291.

Zadeh L. A.(1994), Fuzzy logic, neural network and soft computing. Fuzzy systems, communications of the ACM, Vol. 37, No. 2.

Zadeh L.A., (2010), Toward a Logic of Everyday Reasoning, Logic Colloquium, UC Berkeley, Available from http://www.cs.berkeley.edu/ zadeh/presentations.html

Zhao L., Xu B., Tang W. and Chen Z,(2005), A Pixel-Level Multisensor Image Fusion Algorithm Based on Fuzzy Logic, Fuzzy Systems and Knowledge Discovery, Lecture Notes in Computer Science, Vol. 3613, pp.476, DOI: 10.1007/11539506_89. 


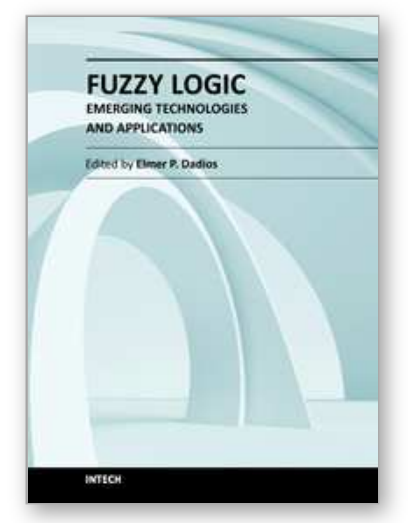

\author{
Fuzzy Logic - Emerging Technologies and Applications \\ Edited by Prof. Elmer Dadios
}

ISBN 978-953-51-0337-0

Hard cover, 348 pages

Publisher InTech

Published online 16, March, 2012

Published in print edition March, 2012

The capability of Fuzzy Logic in the development of emerging technologies is introduced in this book. The book consists of sixteen chapters showing various applications in the field of Bioinformatics, Health, Security, Communications, Transportations, Financial Management, Energy and Environment Systems. This book is a major reference source for all those concerned with applied intelligent systems. The intended readers are researchers, engineers, medical practitioners, and graduate students interested in fuzzy logic systems.

\title{
How to reference
}

In order to correctly reference this scholarly work, feel free to copy and paste the following:

Alejandra A. López-Caloca and Carmen Reyes (2012). Fuzzy Modeling of Geospatial Patterns, Fuzzy Logic Emerging Technologies and Applications, Prof. Elmer Dadios (Ed.), ISBN: 978-953-51-0337-0, InTech, Available from: http://www.intechopen.com/books/fuzzy-logic-emerging-technologies-and-applications/fuzzymodeling-of-spatial-patterns-

\section{INTECH}

open science | open minds

\author{
InTech Europe \\ University Campus STeP Ri \\ Slavka Krautzeka 83/A \\ 51000 Rijeka, Croatia \\ Phone: +385 (51) 770447 \\ Fax: +385 (51) 686166 \\ www.intechopen.com
}

\author{
InTech China \\ Unit 405, Office Block, Hotel Equatorial Shanghai \\ No.65, Yan An Road (West), Shanghai, 200040, China \\ 中国上海市延安西路65号上海国际贵都大饭店办公楼 405 单元 \\ Phone: +86-21-62489820 \\ Fax: +86-21-62489821
}


(C) 2012 The Author(s). Licensee IntechOpen. This is an open access article distributed under the terms of the Creative Commons Attribution 3.0 License, which permits unrestricted use, distribution, and reproduction in any medium, provided the original work is properly cited. 